\title{
Evaluation of nursing care behavior culture program's implementation at Dharmais Cancer Hospital
}

\author{
Tuti Nuraini \\ Faculty of Nursing, Universitas Indonesia, tutinfik@ui.ac.id \\ Enie Novieastari \\ Faculty of Nursing, Universitas Indonesia
}

See next page for additional authors

Follow this and additional works at: https://scholarhub.ui.ac.id/ajce

Part of the Social and Behavioral Sciences Commons

\section{Recommended Citation}

Nuraini, Tuti; Novieastari, Enie; and Yetti, Krisna (2019). Evaluation of nursing care behavior culture program's implementation at Dharmais Cancer Hospital. ASEAN Journal of Community Engagement, 3(1). Available at: https://doi.org/10.7454/ajce.v3i1.140

Creative Commons License

(c) (i) ()

This work is licensed under a Creative Commons Attribution-Share Alike 4.0 License.

This Research Article is brought to you for free and open access by the Universitas Indonesia at ASEAN Journal of Community Engagement. It has been accepted for inclusion in ASEAN Journal of Community Engagement. 


\title{
Evaluation of nurses caring culture behavior program's implementation at Dharmais Cancer Hospital
}

\author{
Tuti Nuraini ${ }^{a^{*}}$, Enie Noviestaria, Krisna Yettia \\ aFaculty of Nursing, Universitas Indonesia \\ Received: December $3^{\text {rd }}, 2018$ || Revised: December 30th, 2018 || Accepted: May 27th 2019
}

\begin{abstract}
Nurses use the concept of caring in providing nursing care. However, factors that influence nurses' caring attitudes, such as job stress and dehumanization, make caring behavior decrease. Previous research showed that $52.9 \%$ of patients reported that the implementation of caring behavior by nurses in Dharmais Hospital was lacking. Our program offers a solution for building a caring culture among oncology nurses. Researcher team activities were carried out, including the socialization of a caring culture with 84 nurses, training for 16 head nurses as the change agent for guiding nurses, and a guidance program for 16 head nurses to act as champion to the rest of the nurses. The researcher evaluated the implementation of caring culture using focus group discussion (FGD) with the 16 head nurses. Eight themes were obtained from the FGD: observation guidance about caring behavior to help champions monitor and increase the nurses' caring attitudes; training about caring to help nurses change their caring attitudes; excessive workload makes nurses display less-caring behavior; the WhatsApp application helps socialize a caring culture; spiritual power from the inside fosters caring behavior; support from hospital leaders is needed to encourage caring behavior; need for caring behavior training and therapeutic communication for all health care providers and administrative staff; and need for caring behavior standard operating procedures (SOP) and guidance from senior nurses. The number of nurses who perform caring well also increased by $38 \%$ after intervention $(p=0.021)$. Based on the FGD results, it was recommended to improve the caring culture behavior in the hospital through several efforts.
\end{abstract}

Keywords: caring culture, oncology nurse, training, champion, Focus Group Discussion (FGD)

\section{Introduction}

The prevalence of cancer is increasing year by year (Oemiati, Rahajeng, \& Kristanto, 2011). This shows that health care services need to be improved to reduce its incidence and the number of deaths it causes. Patients with cancer face physical, psychological, and financial difficulties (Nuraini, Gayatri, \& Irawaty, 2018). In addition, patient's families are burdened and show symptoms anxiety, depression, financial problems, and stress. These complaints need to be treated by the nurses and health care providers. Nurses who care for patients and their families are needed to improve the quality of health care services in Indonesia.

\footnotetext{
*Correspondence Author: tutinfik@ui.ac.id
} 
Caring is an important value in nursing practice. Caring behavior is the essence of nursing care services that makes it different from the other health care services (Watson, 2007; Mc Millan, 2017). Nurses' caring behavior can be seen through empathy, approaching patients without judgment, a warm attitude, respect for clients, unending patience, and having good skills. Patients feel comfortable during treatment if the nurses perform their duties with caring behavior.

Caring behavior is influenced by several types of factors: individual, organizational, and psychological (Pramudjono, 2015; Sibandze, 2018). Individual factors are associated with nurses' ability and skill, their family and working experience backgrounds, and demographics (age, gender, educational background, working period, marital status, and employment status). Organizational factors include resources, leadership, rewards, organizational structure, and job design. Psychological factors are related to perceptions, attitudes, learning desires, personality, and motivation.

Nursing is a profession with a moral responsibility to maintain and improve the public health status. Nurses are expected to provide good nursing care services to achieve optimal client health. Some nurses do not fully implement caring behavior while they are doing their job. Previous research shows that $52.9 \%$ of Dharmais Hospital patients reported that the implementation of caring behavior by nurses was lacking (Talenta, 2016).

Non-optimal caring behavior by nurses who work in a cancer ward is caused by work stress and the continuous exposure to grief or news of death. These conditions can lead to a decrease in empathy and caring behavior. If this is not brought to attention, it can affect patient satisfaction (Bucco, 2015) and nurses' working motivation, which ultimately reduces health service quality. In addition, a suboptimal implementation of caring behavior creates less trust between nurses and patients, longer physical healing times, and the loss of the patient's sense of security and comfort (Watson, 2007). Other studies show that caring behavior can reduce anxiety for pre-operative patients, increase the patient's loyalty to nurses, and shorten the length of stay (Aliftitah \& Suprayitno, 2017; Rufaidah, Qurrotul, \& Istioningsih, 2018). These results show that nurses' caring behavior significantly impacts patients and health services. Therefore, caring behavior needs to be improved to improve patient comfort and health service quality. 
Tuti Nuraini, Enie Noviestari, Krisna Yetti | ASEAN Journal of Community Engagement | Vol. 3, No. 1, 2019

Caring behavior by nurses needs to be nurtured. Several theories posit the reinforcing factors of forming a person's behavior, including praise (The Operant Conditioning Theory), practice (Pavlov's and Thorndike's theories), and individual intellectual development factors (Piaget's theory). According to the Health Belief Model (HBM) theory, behavior is set according to an individual's belief. Behavior can also be formed on the basis of behavioral intentions as described in the Theory of Planned Behavior, which was developed from the Theory of Reasoned Action (Ajzen, 1991). Based on these theories, individual behaviors are based on two major sources: cognitive theory and stimulus respond theory.

Health practitioners and educators commonly use the HBM to design and evaluate behavior-shaping interventions (Glanz, Rimer, \& Viswanath, 2008). This model is based on the understanding that people are motivated to act based on their concern for health. Internal motivation is controlled by an individual's ethics or values of individual behavior (Marquis \& Huston, 2015). This theory furthermore suggests that changing individual knowledge and behavior is easier than changing group attitudes and behavior. The key concept of the HBM influences individuals to determine and choose good actions (Glanz et al., 2008). This concept includes perceived barriers and benefits and cues to action. That is, understanding the cues to elicit the correct level of acceptance regarding the vulnerability of hazards, benefits, and barriers to action.

An individual who believes that caring for another vulnerable or sick human is a rewarding thing, he/she may be more likely to act in that way. This behavior certainly benefits people who need help. Every individual action or behavior is basically driven by internal or external motivation. Other influencing factors include a person's cognitive ability and self-regulation. An individual's behavior is influenced by the response patterns of others (Handiyani, Kurniawidjaya, Irawaty, \& Damayanti, 2017). They recommend a social learning theory approach (Bandura's Theory) for forming behavior. This is because reciprocal relationships and interactions among cognitive, environmental, and behavior influences form the basis for individual behavior (Bandura, 1978). The researcher team used the champion formation approach to shape behavior. Champions are expected to be able to influence the people around them to have caring behavior.

In this program, we apply experts' Watson and Swanson's concept of caring. In the implementation, we adjust the concept for conditions in Indonesia. Caring is generally 
defined as one of these abilities: to be dedicated to others, show attention, feel empathy, feel love or affection, and have to have a relationship with others (Potter \& Perry, 2009). Patients with cancer need greater care compared to other patients (Novieastari \& Gunawijaya, 2017). Therefore, oncology nurses must perform caring behavior for cancer patients, and the hospital must develop and support a caring environment to create a supportive caring foundation for the nurses.

The pioneer of caring theory, Jean Watson explained that caring is central to nursing practice because it requires a dynamic approach; nurses cannot do their job without caring for patients. Therefore, caring is an action that provides the basis of nursing services for clients by fulfilling their health care needs. Watson stated that the core of nursing is helping clients to reach higher levels of mind, body, and spirit harmonization, which can be achieved through caring transactions (Tomey \& Alligood, 2010). Watson describes the 10 "carative" (related to caring) factors as follows: to form humanistic and altruistic values; to create hope and expectations; to foster sensitivity to oneself and to others; to develop a relationship of mutual help and mutual trust; to enhance and accept the expressions of positive and negative feelings; to use scientific and systematic problem-solving methods to make decisions; to improve the interpersonal teaching and learning process; to create supportive, protective, and corrective physical, mental, sociocultural, and spiritual environments; to help fulfill basic human needs; and to appreciate the existence of power from spiritual phenomena.

Kristen Swanson's theory is slightly different from Watson's. Swanson believes that caring contains five categories or components. These components are integrated and related to each other and cannot stand alone. The process of merging these components forms a nurse's caring behavior (Potter \& Perry, 2009). Swanson's caring components are knowing, being with, doing for, enabling, and maintaining belief (Alligood, 2014). Knowing means understanding the events patients are experiencing, avoiding making assumptions, focusing on patients, making in-depth assessments, seeking clues, and getting involved.

Being with means that the nurses' emotions are present; they are being there when they are needed, sharing feelings, not creating a burden, and conveying abilities. Doing for means doing something as if it were for oneself, staying calm, anticipating, doing something based on ability, and maintaining and protecting dignity. Enabling means facilitating life transitions and unusual events, informing, explaining, and supporting, 
providing alternative solutions, and validating and giving feedback. Lastly, maintaining belief means maintaining trust, a hopeful attitude, and optimism. These theories and concepts of caring form the underlying basis for the program implementation of developing caring culture behavior for nurses in the hospital.

The goal of the program activity is to improve caring behavior of oncology nurses through strengthening nurse and hospital engagement. And, training alone is not enough to improve caring behavior. First, it should be made part of the organization's culture, which requires support from relevant stakeholders (Glembocki \& Dunn, 2010). In this community engagement project, we used several approaches to garner support, including nurse training, champion formation, and reform agents who guide and assess nurses' caring behavior. At the end of the program, after two months of implementation, the program was evaluated through FGD.

\section{Methods}

Our program provides a solution for optimizing the caring culture of oncology nurses, specifically nurses who work at Dharmais Cancer Hospital (RSKD). The targets of our program were practical nurses and head nurses who would become champions, responsible for guiding and assessing oncology nurses. The results of workforce analysis at RSKD showed that of approximately 300 nurses, the majority have education that resulted in a diploma. There were approximately 22 head nurses for the outpatient and inpatient wards. There were 84 nurses involved in this activity and 16 head nurses. The head nurse and the nurses who participated in training were tasked with disseminating information to their colleagues who have not yet received training.

The researcher designed the application of this caring concept in several phases. The first phase was coordination with the Nursing Division (Bidper) and Training Education Division (Diklat) at RSKD. The next activity was socialization and training for 84 oncology nurses about caring cultural awareness. The third phase was to train 16 head nurses who would guide and assess the nurses' caring behavior. The instrument used for assessing caring behavior was the Caring Behavior Inventory (CBI). The following guidance was provided for the head nurse in acting as a reformer champion agent to improve caring behavior for oncology nurses. The role of champion provides guidance for approximately two months. This guidance was based on versions of Swanson and 
Watson's caring theories that were modified to make it easier for nurses to apply. The guidance for observing nurse caring behavior included 41 items.

Table 1. Guidance for Observing Nurse Care Behavior

\section{Guidance for Observing Nurse Care Behavior}

1 Call the patient by name, respecting any nicknames

2 Respond to patient's calls immediately

3 Listen to the patient's problems and needs patiently

4 Recognize the patient's advantages and disadvantages

5 Give full attention to the patient

6 Explain the patient's current condition

7 Explain each procedure every time nurses want to do an intervention

8 Provide support and show enthusiasm for the patient's healing process

9 Motivate the patient to do positive things which can be beneficial for the healing process

10 Help the patient when they face problems

11 Respond quickly to the patient's complaints and needs

12 Show patience when dealing with the patient's complaints and attitudes

13 Introduce yourself at the first interaction with the patient

14 Explain the nurses' role in the patient's care process

15 Talk to the patient patiently and politely

16 Show empathy and a warm attitude to the patient

17 Show the attitude of being ready to help if needed by the patient

18 Observe the patient's condition routinely as scheduled

19 Respect the patient's privacy by closing the curtain when bathing the patient, for example

20 Give the patient time to express their feelings 


\section{Guidance for Observing Nurse Care Behavior}

21 Encourage the patient to express both positive and negative feelings

22 Listen to the patient's complaints with full attention

23 Do further assessment of the patient's problems

24 Create a diagnostic and nursing care plan for the patient

25 Perform nursing care in accordance with the nursing plan

26 Evaluate the nursing care that has been given thus far

27 Involve the patient and family in providing nursing care

28 Ask the patient what questions they have about problems associated with the healing process

29 Give a rational explanation when the patient asks about the disease's progression and how to overcome it

30 Guide the patient on how to fulfill their own needs independently according to their abilities

31 Provide patients with health education related to their illness

32 Facilitate the patient's need to meet with religious leaders

33 Help the patient to pray if needed

34 Encourage the patient to pray according to their religion

35 Help the patient contact their family if needed

36 Help the patient fulfill their basic nutrition, elimination, hygiene, and other needs if the patient is unable to do so by themselves

37 Pay attention to the patient's environmental security and comfort such as room cleanliness, installation of bed side rails, observation of medical devices used by the patient, etc.

38 Observe the patient's health condition routinely and regularly

39 Facilitate the patient's ability to fulfill their need for the healing process

40 Support the patient in enduring the disease

41 Motivate the patient to return everything to God 


\subsection{Data collection}

Eight participants were recruited for each of the two focus groups. The interview technique used was focus group discussion or FGD. The FGD technique was useful for efficiently assessing information. With a dynamic group, it was able to overcome the participants' introversion, resulting in the collection of enough information.

FGDs were held in August 2018 in the RSKD Diklat room. All participants in each focus group were interviewed for 100 total minutes. The team recorded the conversation and transcribed the information provided by the participants. Participants' responses were video, and audio recorded for verbatim transcription. Interviews were carried out until all desired data was obtained.

\subsection{Analysis}

The FGD used a thematic analysis technique. The data analysis employed a coding process with systematic steps. The activity began with data organization and preparation, reading all the data, and coding (Creswell, 2014). Computer software was used for coding. The researchers made a transcript of data from each FGD. The stages in data analysis included: listening to participants' verbal descriptions, making a list of significant statements, and creating themes. The researcher read the transcriptions line by line, marked key words, categorized them, and defined themes from several categories.

\subsection{Ethical considerations}

The Ethic Committee Faculty of Nursing University of Indonesia conducted a thorough ethical review.

\section{Results and Discussion}

Sixteen head nurses were recruited for this activity. The age range of participants was 30-50 years, with an average age of 42.5 years and a standard deviation of 5.47. The majority of participants were female (12 or 75\%), and 12 participants (75\%), held Bachelor of Nursing (S.Kep) and Professional degrees (Ns).

Furthermore, we evaluated the results of program implementation using two FGDs. Each FGD was comprised of eight nurses. The following questions were addressed in the 
Tuti Nuraini, Enie Noviestari, Krisna Yetti | ASEAN Journal of Community Engagement | Vol. 3, No. 1, 2019

FGD: (1) What is the strategy to form a nurse's caring culture after training and after two months of program implementation?; (2) What has been done to form a nurse's caring culture?; (3) What are the factors that influence its successes and failures?; (4) What is the response from nurses and other health care providers to your efforts?; (5) What are the obstacles to establishing a caring culture?; (6) How can these obstacles be overcome?; (7) What is a head nurse's role in forming a caring culture?; (8) What are your suggestions for institutions, hospitals, and nurses?

The results of the qualitative study from the FGDs produced the following eight themes:

1) Observation guidance about caring behavior to help champions monitor and increase nurses' caring attitudes;

2) training about caring to help nurses improve their caring attitudes;

3) excessive workloads create less-caring behavior;

4) the Whatsapp application helps socialize a caring culture;

5) spiritual power from the inside fosters caring behavior;

6) support from hospital leaders for caring behavior;

7) needs for caring behavior training and therapeutic communication for all health care providers and administrative staff;

8) needs for caring behavior standard operating procedures (SOP) and guidance from senior nurses.

\subsection{Observation guidance about caring behavior to help champions monitor and increase} the nurses' caring attitudes

In the FGD, the head nurse described his experience conducting assessments of caring behavior displayed by their subordinates. The head nurse's statement was as follows:

“...... After joining the caring culture training, we immediately applied it. The nurses who joined the training share the knowledge with nurses who did not participate. When giving an assessment, don't feel bad when evaluating caring behavior. Make an assessment as it is ...... (N1)"

"..... Three months of observation is enough to increase caring behavior. After training, many nurses provide time to listen to patients' feelings (N2)" 
"...... So, for the nurses, caring behavior could be seen from the patient's condition

when nurses do a handover and from the number of complaints from the patient and family. (N10) ......"

The head nurse felt that became easier to apply and teach the concept of caring to his staff with the guidance of caring behavior. The unclear concepts of caring must be applied in an easy way so that everyone can feel the benefits (Drake, 2016; Sibandze, 2018). According to Drake (2016), nurses can change their caring behavior using evidence-based practice models. Nurses need clear guidance to apply the caring concepts that various experts have described.

The head nurse felt that three months was enough to make effective changes in caring behavior using this program. Head nurses were provided with the concept of change to create better caring behavior by trainees. The process of change can be planned (Planned change) where certain activities are completed with the intention of achieving certain goals or objectives. To make an effective change, a change agent plays a role in managing the change to achieve the expected goals (Robbins \& Judge, 2017). Change agents are people who act as drivers of change and who are responsible for managing change activities (Robbins \& Judge, 2017). In this program, we appointed head nurses as change agents. In their role as change agents, they worked to form a caring culture using the following methods: (1) Diagnosing the problem; (2) Building a relationship of trust and partnership; (3) Explaining the vision of the need for change; (4) Creating an agenda; (5) Solving problems; (6) Implementing the change plan; (7) Having a vision for the future of the organization; (8) Motivating others to participate in creating and implementing that vision. Therefore, to achieve a culture of caring, the role of change agent or head nurse is very important in motivating, creating, and implementing the vision.

We call change agents "champions." A champion is a person who successfully optimizes others' potential and trains others to achieve their best performance. A champion is also a person who can increase the quality of staff commitment and contribution, allowing them to be more involved in line management, to create workforce contributions within the organization, and to be able to understand and meet 
staff needs. Every individual has the inherent capability to be a champion, especially team leaders.

A champion also plays a role in forming a caring culture. Tomey \& Alligood (2010) state that caring cannot be passed down from one generation to the next through genetics, but through professional culture. Professional culture can be achieved by cultivating a spirit of caring among nurses through a continuous process of socialization, management, cooperation, symbols, and rituals or habits. Nurse leaders or head nurses in this program have an important role in improving the health of patients and staff through the delivery of behavior change intervention (Fuller, 2015).

\subsection{Training about caring to help nurses change their caring attitudes}

Training can change both knowledge levels and behavior. The head nurses' experience of applying changes in caring behavior showed that it greatly helped that the nurses had already attended the previous caring training. Here are some observations by the head of the room:

“...... After taking the caring culture training, I applied it immediately. Nurses who took the training shared their knowledge with nurses who did not participate ...... (N1)"

"..... After training, many nurses provide time to listen to patients express their feelings ...... (N2)"

"..... In my opinion, if we want to influence other people to build a caring culture, we must start with ourselves first and show them that we care about patients ...... (N10)" “..... Caring culture starts from the handover activity. We are habituated to greeting and praying in the morning. Then there is another activity which problem is solving or preconference about things that happened yesterday afternoon ...... (N12)"

“...... Basically, my nurse friends have done it from pre-interaction, greeting with smiles until spiritual things were facilitated. In the ICU, the nurses' concerns about critical patients are facilitated, so that patients have psychological contact with their families (N13)"

“...... With the training that has been done yesterday, we have made small changes. For example, when we accompany and help a patient in a wheelchair, we pay 
attention to make the patient comfortable by explaining that the patient must be ready when the road slopes down or there are obstacles on the road ...... (N12)"

Changes in caring behavior were aligned with the increased knowledge of caring after training. The number of nurses who had improved caring also increased by approximately $38 \%$ after intervention $(\mathrm{p}=0.021$ ) (See Table 2 ).

Table 2. Description of changes in perceptions of caring behavior of oncology nurses

\begin{tabular}{cccc}
\hline Variable & Pre-intervention & Post-intervention & $\mathrm{p}^{*}$ \\
\hline $\begin{array}{c}\text { Less-caring } \\
\text { behavior }\end{array}$ & $62 \%$ & $24 \%$ & \\
$\begin{array}{c}\text { Good caring } \\
\text { behavior }\end{array}$ & $38 \%$ & $76 \%$ & 0.021 \\
\hline
\end{tabular}

*Wilcoxon test cut of point $70 \%$.

Source: belongs to researcher (2018)

The researcher conducted caring training behavior for nurses and champions (See Figure 3.2). This activity was also supported by hospital leadership. Training with expert resources in the field of caring greatly improves knowledge and behavior levels (Ramchandran \& Von Roenn, 2013). In this caring culture training program, we assigned caring culture experts and nursing management experts in Indonesia as resources. Dr. Krisna Yetti is the chair of the Indonesian nursing ethics committee; Dr. Enie Novieastari is a cultural expert in nursing care; Dr. Tuti Nuraini is an expert on comfort instruments for cancer patients; and Dr. Hanny Handiyani is a change management expert. Resource persons who are experts in their fields can improve caring behavior in others. Training can also improve emotional intelligence, which can affect behavior (Johnson, 2017). 
a.

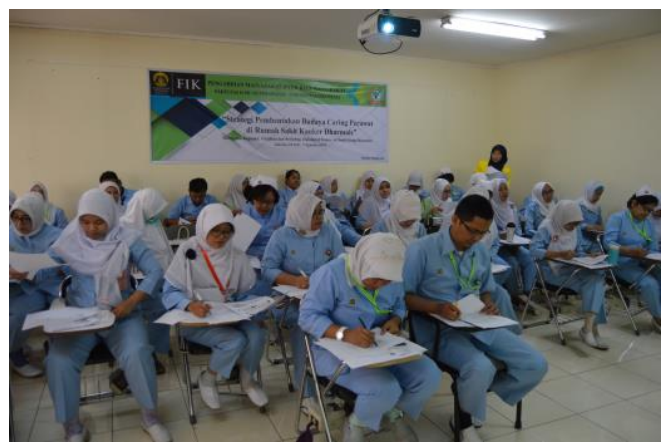

b.

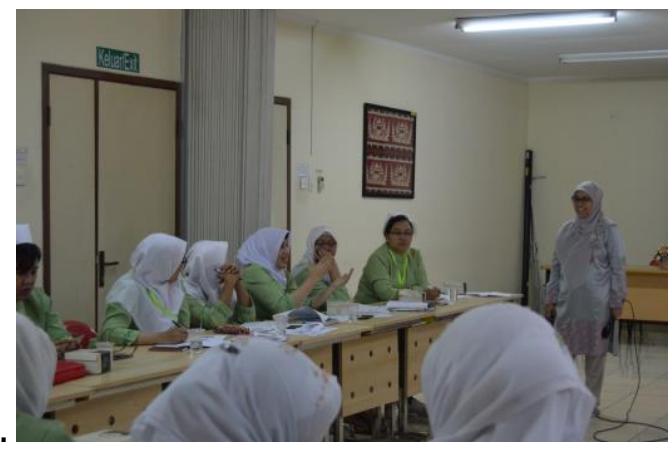

Figure 3.2 (a) first picture; (b) second picture Source: Authors (2018)

\subsection{Excessive workload causes nurses to display less-caring behavior}

Participants emphasized the importance of caring behavior. Refresher training reminded them about the importance of caring behavior in taking care of cancer patients. However, excessive workload causes nurses to be unable to carry out caring behavior in accordance with the provided guidelines. The following are explanations from the head nurse about why this can happen:

“..... Caring behavior is of value of nurses, especially oncology nurses, the caring value must be higher than other nurses. But excessive workload can cause less attention ...... (N4)"

“...... After the training, nurses' colleagues applied caring behavior according to the guidelines, but because there were many patients, about 300 people per day, time after time they forgot to apply it anymore (N4)"

“...... Most of my colleagues have done it, but the time is lacking because there are many other works demands (N5)"

“..... A lot of work is outside of nursing duties, but should this be gets done by the nurses (N6)"

“...... Sometimes the failure factor is when we handover, we found the patient's needs have not been fulfilled. Then we examine why; it turns out that one nurse worked on five total care patients (N12)"

“..... Overseas, nurses can focus on caring because they are not burdened by other cases, but in Indonesia there are things that affect it ...... (N14)" 
“..... I do not ask much from my nurse, if she is still taking care of me, it is already extraordinary seeing that nurses have many patients. It is already great if the nurses are not frowning at patients (N14)"

“...... Everything becomes our tasks. Light problems, water, bed, everything becomes our tasks ...... (N16)"

Nurses know and are eager to apply the caring concept, but their heavy workload impedes their ability to do it well. Fatigue is one factor that affects someone's ability to care, but great affection can defeat fatigue (Sibandze, 2018). Nurses understand the importance of applying caring concepts in carrying out nursing care, but excessive workload makes them unable to apply the concepts optimally. In nursing care management, it is necessary to consider the maximum workload that nurses can handle. Nurses workload calculations are a concern for hospital leaders in the effort to create an optimal working situation for nurses. Although nurses feel these large workloads are an obstacle to carrying out caring behavior, the compassion they feel makes them do their best work. Compassion, comfort, and competence can help keep nurses applying caring concepts in their work (Feudtner et al., 2007; Drake, 2016).

\subsection{The WhatsApp application helps socialize a caring culture}

Technology advancements affect communication patterns. Socialization is made easier by existing technology. Currently, the distribution of information is easier using the WhatsApp (WA) application. This application can contribute to the successful dissemination of a more caring culture.

“...... Regarding the success of socialization with existing facilities, especially through the WA group, actually everything is already exposed ...... (N13)"

“...... Keep reminding health team about strategy. Then don't forget to always make a coordination in health team (N13)"

Cancer patients and families expect to receive quality health services. Effective coordination is needed so that the health team can provide patients with quality health services. The health team can use communication technology such as WhatsApp to maintain effective communication and provide optimal health services. Generally, when 
sick patients and their families arrive at the hospital, they do not know what to do. The health team providing meaningful and accurate information can help improve patient health. Using WhatsApp to coordinate communication worked effectively. Sophisticated use of the internet has been proven to improve health services (Yoo et al., 2013). Nurse caring behavior can be demonstrated by good communication and coordination.

\subsection{Internal spiritual power fosters caring behavior}

Almost all participants were highly spiritual and transmitted these abilities to their colleagues and subordinates. In fact, this has become the most important thing in helping oncology nurses in Indonesia develop caring behavior. Indonesia is a country with many religious citizens, so spiritual ability is an important part of daily life. The following are the participants' statements relating to the spiritual ability of building caring behavior:

"...... We always remind ourself that the goal of working is to find rewards from God (N1)"

“...... We do not deserve a complaint because God has given many gifts (N4)"

"..... I am interested in doing Morning Gratitude (giving thanks and praying in the morning) before starting work. Pray that no patient will complain (N5)"

"..... Always pray for patience because all VIP patients ask for special services. Do your best, we will reap it ...... (N7)"

"..... Caring is from the heart, it cannot be forced, it must be a lot of gratitude ...... (N6)"

"..... Give as much as we can, let God judge. We almost never go home on time ...... (N6)"

"..... Remind each other, what if you were in the patient's position? ...... (N8)"

Spiritual strength and self-awareness are a significant part of emotional intelligence. High emotional intelligence is proven to improve empathy and caring behavior (Johnson, 2017). Spiritual ability is part of the strength Indonesian nurses have in caring for patients. Indonesians believe that there is life after death, and that if someone behaves well toward others, it will positively affect his life after he dies. 
This spiritual power allows nurses to provide the best service for patients. Indonesia is a country with several religions, but the majority are Muslim. Muslims emphasize that work is worship, not only for earning money or income. Islam also emphasizes that one should compete in goodness. Thus, Muslim nurses are happy to provide the best service because they remember that the purpose of life is worship. Spiritual strengthening is important and hospital leaders should be concerned with helping their employees develop it.

\subsection{Support from hospital leaders for caring behavior}

Hospital leaders certainly support the formation of caring behavior. Caring behavior is an important component in hospital accreditation, both nationally and internationally. However, according to participants, giving rewards is also important for nurses with disciplined and dedicated caring behavior. The following are verbatim results from the interview with head nurses in the FGD:

“..... Caring activities are in line with the activities of the nursing committee, who are surveying about caring ...... (N8)"

“...... Always be reminded that caring culture must be consistent. Caring behavior is included in the JCI Hospital assessment ...... (N1)"

"...... There has been no reward from the hospital, as the nurse announced with the criteria of caring, discipline, and responsibility (N1)"

"..... Oncology nurses need capacity building and gathering to avoid boring ...... (N4)"

“..... This suggestion is about the fulfillment of human resources proportions. So, that there is no reason for the nurse to be busy with many patients. The patients here are patients with partial care with the infusion installed. After chemotherapy, the patient is weak and nauseous, so they need nurses (N13)"

“...... Need facilities that can support the nursing service (N13)"

“...... Reinforcement for the responses of nurses that do cultural things is a positive thing ...... (N14)"

The hospital's policy certainly affects changes. The hospital's support of the nurses is an important aspect that determines success. Advanced communication skills, 
knowledge of business principles, finances, and health policy affect how services are provided to patients (Walker \& Polancich, 2015).

The hospital leadership strongly supports the program for caring behavior. The nurses' suggestions are very meaningful to them. These suggestions are taken into consideration so that the hospital leadership can determine the next strategy. Thus, candid and open communication is needed between hospital leaders and subordinates. Subordinates can provide input to leaders and leaders can accommodate input from subordinates to ensure good service production. The results of previous studies show that there is a positive relationship between nurse leadership style, span of control, staff nurse practice environment, climate safety, and nurse-sensitive patient outcomes (Merrill, 2011).

\subsection{Needs for caring behavior training and therapeutic communication for all health care providers and administrative staff}

Caring behavior is not only required from nurses; health professionals and other health care providers who work in hospitals also need to show caring behavior. Participants provided opinions about how caring behavior training was needed for all health care providers and administrative staff who work in hospitals to achieve the hospital's vision and mission.

“...... Caring behavior training and therapeutic communication need to be done for all health care providers other than nurses, such as doctors, radiographers, physiotherapists, and hospital administrative staff ...... (N5)"

“..... From my experience in the polyclinic, sometimes this complaint is not directed at the nurses but at the doctor, who often comes late (N10)"

All hospital staff should demonstrate caring behavior, not only nurses. Therefore, all staff who are involved in providing service to patients must demonstrate caring behavior. The results of this study prove an increase in nurse caring behavior by $37 \%$, in line with previous studies conducted by Glembocki \& Dunn (2010). Reigniting the Spirit of Caring from Creative Healthcare Management would enhance the perception of caring behavior as an educational intervention (Glembocki \& Dunn, 2010). McMillan (2017) explains that organizational values should also be in accordance with 
organizational standards; namely accountability, integrity, stewardship, teamwork, and respect (McMillan, 2017). These values improve quality patient care by implementing caritas processes from Watson's Theory of Human Caring (McMillan, 2017). The results of this study make it clear that caring behavior must be shared by all health teams, not just nurses.

3.8. Needs for standard operating procedures for caring behavior and guidance from senior nurses

Participants shared the opinion that even though nurses and head nurses had joined the training sessions, not all of them could run optimally because of some obstacles. Therefore, participants suggested that SOP need to be created for caring behavior. In addition, young inexperienced nurses must be guided by senior nurses who have experience with the implementation of caring behavior.

“...... Nurses' work has not been directed, work is still about routine, caring awareness is still rare ...... (N1)"

“..... SOP for caring does not exist yet; providing time for patients to express their feelings is still lacking ...... (N2)"

“..... Guidance from senior nurses is needed by young nurses who do not have experience exploring patient problems (N8)"

“...... Sometimes time and patience are reduced because you listen too long to patients and family ...... (N5)"

The need for guidance to continue demonstrating caring behavior is part of the change to make it better. As humans, nurses must be reminded constantly so they will not forget. Familiarizing themselves with a clear SOP guide will help nurses change gradually and ensure that previous behaviors will not return.

Guidance from senior nurse leaders is also important in the process of younger nurses forming caring behaviors (Fuller, 2015). More senior nurses have more experience and are expected to transmit it to younger nurses. 
Tuti Nuraini, Enie Noviestari, Krisna Yetti | ASEAN Journal of Community Engagement | Vol. 3, No. 1, 2019

\section{Conclusion}

All nurses are aware of the importance of caring behavior in providing nursing care services. Training and guidance from champions or experts are very useful for reminding them of the importance of caring behavior. However, there are still some obstacles that must be overcome in order to improve caring behavior of all hospital staff, including excessive workloads, lack of experience, lack of reward by leaders, and other untrained staff. Conversely, spiritual power is a positive aspect in an individual that strengthens caring behavior. This spiritual ability must be improved continuously through various spiritual enhancement activities.

Cancer patients and families experience hard times in their life. They deserve to have quality health care services. Caring behavior by health care providers is what they expect to reduce the burden of suffering they experience during their illness.

\section{References}

Ajzen, I. (1991). The theory of planned behaviour. Organizational Behaviour and Human Decision Process, 211(50), 179-211.

Alligood (2014). Nursing Theorists and Their Works. Eighth Edition. St. Louis: Mosby Elsevier, Inc.

Aliftitah, S., \& Suprayitno, E. (2017). Hubungan Perilaku Caring Perawat dengan Kecemasan Pasien Pra Operasi Di Ruang Bedah Rsud Dr. H. Moh. Anwar Sumenep. Jurnal Ilmu Kesehatan, 2(1), 17-22.

Bandura, A. (1978). The self system in reciprocal determinism. American Psychologist, 33(4), 344-358. Retrieved from https://doi.org/10.1037/0003-066X.33.4.344

Bucco, T. (2015). The Relationships between Patients'Perceptions of Nurse Caring Behaviors, Nurses'Perceptions of Nurse Caring Behaviors and Patient Satisfaction in The Emergency Department. UMI Dissertation Publishing. Seton Hall University. Retrieved from ProQuest LLC

Creswell, J. W. (2014). Research design-qualitative, quantitative, and mixed method approaches. Los Angeles: SAGE Publication, Inc.

Drake, J. (2016). Tools That Measure Caring: A Systematic Literature Review of the Impact of Caring. Walden University. Retrieved from ProQuest LLC

Feudtner, C., Santucci, G., Feinstein, J. A., Snyder, C. R., Rourke, M. T., \& Kang, T. I. (2007). 
Tuti Nuraini, Enie Noviestari, Krisna Yetti | ASEAN Journal of Community Engagement | Vol. 3, No. 1, 2019

Hopeful thinking and level of comfort regarding providing pediatric palliative care: a survey of hospital nurses. Pediatrics, 119(1), e186-e192. http://doi.org/10.1542/peds.2006-1048

Fuller, S. (2015). The role of nurse leaders in improving health. Nursing Times, 111(3), 12-14.

Glanz, K., Rimer, B. K., \& Viswanath, K. (2008). Health behavior and health education: Theory, research, \& practice (4 th). San Francisco: Jossey-Bass.

Glembocki, M. M., \& Dunn, K. S. (2010). Building an Organizational Culture of Caring: Caring Perceptions Enhanced with Education. The Journal of Continuing Education in Nursing, 41(12), 565-570. http://doi.org/10.3928/00220124-20100701-05

Handiyani, H., Kurniawidjaya, M., Irawaty, D., \& Damayanti, R. (2017). Model Pembelajaran Berbasis Keselamatan untuk Membentuk Perilaku Mencegah Cedera Jarum Suntik Mahasiswa Keperawatan di Wahana Praktik. Universitas Indonesia.

Johnson, D. G. (2017). Emotional Intelligence and Caring Behaviors: Is There A Relationship? Gardner-Webb University Hunt School of Nursing. Retrieved from ProQuest LLC

Marquis, B. L., \& Huston, C. J. (2015). Leadership roles and managment functions in nursing: Theory and application (8th ed.). Philadelphia: Wolters Kluwer Health. Lippincott Williams \& Wilkins. Retrieved from www.ebook777.com

Mc Millan, M. O. (2017). The Effects of Watson's Theory of Human Caring on the Nurse Perception and Utilization of Caring Attributes and the Impact on Nurse Communication. Gardner-Webb University Hunt School of Nursing in. Retrieved from ProQuest LLC

Merrill, K. C. (2011). The relationship among nurse manager leadership style, span of control, staff nurse practice environment, safety climate, and nurse-sensitive patient outcomes. The University of Utah.

Novieastari, E., \& Gunawijaya, J. (2017). Buku Pedoman Asuhan Keperawatan Peka Budaya pada Pasien Berpenyakit Kronis. Jakarta, Indonesia: Fakultas Ilmu Keperawatan Universitas Indonesia.

Nuraini, T., Gayatri, D., \& Irawaty, D. (2018). Validity and reliability of the Comfort Assessment Breast Cancer Instrument in breast cancer palliative care. Enfermeria Clinica, 28. http://doi.org/10.1016/S1130-8621(18)30059-7 
Tuti Nuraini, Enie Noviestari, Krisna Yetti | ASEAN Journal of Community Engagement | Vol. 3, No. 1, 2019

Oemiati, R., Rahajeng, E., \& Kristanto, A. Y. (2011). Prevalensi Tumor dan Beberapa Faktor yang Mempengaruhinya di Indonesia. Buletin Penelitian Kesehatan, 39(4), 190-204.

Potter, P., \& Perry, A. (2009). Fundamental of Nursing: Concepts, Process, and Practice (7th ed). Singapore: Elsevier.

Pramudjono, P. (2015). The Influences of Organizational Culture, Moral Hierarchy Level, and Motivation towards the Teacher's Commitment. American Journal of Educational Research, 3(1), 20-24. http://doi.org/10.12691/education-3-1-5

Ramchandran, K., \& Von Roenn, J. (2013). Palliative care always. Oncology (Williston Park), 27(1), 3-6, 27-30, 32-4.

Rufaidah, S., Qurrotul, A., \& Istioningsih, I. (2018). Hubungan Perilaku Caring Perawat Dengan Los (Length Of Stay) pada Pasien Rawat Inap. Jurnal Keperawatan, 10(1), 44-52.

Sibandze, B. T. (2018). The process by which nurses in swaziland develop a values-based practice: a mixed-methods study. George Mason University. Retrieved from ProQuest LLC

Talenta, C. (2016). Hubungan Burnout dengan Perilaku Caring Perawat di Rumah Sakit Kanker Dharmais Jakarta. Universitas Indonesia, Jakarta, Indonesia.

Tomey, A. M., \& Alligood, M. R. (2010). Nursing theorist and their work (7 th edition). St. Louis: The C.V Mosby Elsevier.

Walker, D. K., \& Polancich, S. (2015). Doctor of nursing practice: the role of the advanced practice nurse. In Seminars in Oncology Nursing (Vol. 31, pp. 263-272).

Watson, J. (2007). Watson's Theory of Human Caring and Subjective Living Experiences: Carative Factors. Texto Contexto Enferm, Florianopolis, 16(1), 129-35. http://doi.org/10.15680/IJIRSET.2015.0402009

Yoo, W., Chih, M. Y., Kwon, M. W., Yang, J., Cho, E., McLaughlin, B., ... Gustafson, D. H. (2013). Predictors of the change in the expression of emotional support within an online breast cancer support group: A longitudinal study. Patient Education and Counseling, 90(1), 88-95. http://doi.org/10.1016/j.pec.2012.10.001 